Competing interests: CM intends to set up a biotech company for global marketing of an adenovirus vector for human transfection with the resolve gene of lemmings, which is upregulated by simultaneous serum uisge beatha and Wernicke area AuldLangSyne detection. Well, maybe, if he gets round to it.

1 Fielding H. Bridget Jones's diary: a novel. London: Picador, 1996.

2 Moss PJ, Lambert TW, Goldacre MJ, Lee P. Reasons for considering leaving UK medicine: questionnaire study of junior doctors' comments. $B M J$ 2004;329:1263-5.

3 Coebergh JA. More than words? [Electronic response to Moss et al]. BMJ 2004. bmj.bmjjournals.com/cgi/eletters/329/7477/1263.
4 Lambert TW, Goldacre MJ, Parkhouse J. Intentions of newly qualified doctors to practise in the United Kingdom. BMJ 1997:314:1591-2.

Goldacre MJ, Turner G, Fazel S, Lambert T. Career choices for psychiatry: Goldacre MJ, Turner G, Fazel S, Lambert T. Career choices for psychiatry:
national surveys of graduates of 1974-2000 from UK medical schools. $B r$ national surveys of graduates of 1974-2000 from UK medical schools. $\mathrm{Br}$
JPsychiatry (in press).

6 Sheeran P. Intention-behavior relations: a conceptual and empirical review. Eur Rev Soc Psychol 2002;12:1-36.

Perugini M, Bagozzi RP. The distinction between desires and intentions. Eur J Soc Psychol 2004;34:69-84.

8 Weinberg A, Creed F. Stress and psychiatric disorder in healthcare professionals and hospital staff. Lancet 1999;355:533-7.

9 Dewitte S, Schouwenburg HC. Procrastination, temptations, and incentives: the strugele between the present and the future in

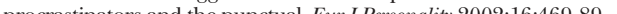

\title{
Out of body experiences and their neural basis
}

\author{
They are linked to multisensory and cognitive processing in the brain
}

"I

was in bed and about to fall asleep when I had the distinct impression that I was at the ceiling level looking down at my body in the bed. I was very startled and frightened; immediately (afterwards) I felt that I was consciously back in the (body on the) bed again." Out of body experiences, as described by a person here, are characterised by a location of the self (or one's centre of awareness) outside one's body, an impression of seeing the world from an extracorporeal elevated perspective, and an impression of seeing one's own body from this perspective. ${ }^{1-3}$ They are striking phenomena because they challenge the experienced spatial unity of self and body-or the experience of a real me that resides in one's body and is the subject of experience and action. ${ }^{45}$ Recent neurological evidence shows that these experiences are related to an interference with the temporo-parietal junction of the brain.

A better understanding of out of body experiences might further our scientific concepts about self and body and their experienced spatial unity. These have been influenced by diverse fields such as theology, philosophy, and psychology as well as neurology and psychiatry. ${ }^{1-7}$ Out of body experiences occur in about $10 \%$ of the population, most of the world's cultures, and several medical conditions. ${ }^{1-3}$ To date only few scientific investigations have been carried out on out of body experiences, probably because they generally occur spontaneously, are of short duration, and happen only once or twice in a lifetime. ${ }^{12}$ Investigations of neurological patients with out of body experiences are also rare, but they have several advantages. Out of body experiences in these patients might occur repetitively, sometimes in short succession, allowing for more detailed questioning of the experiences and associated sensations shortly after they occur. Moreover, researchers can analyse the associated neurological, causative, and anatomical findings.

Some clinicians have observed out of body experiences in association with various neurological conditions, but mainly in epileptic seizures and migraine. ${ }^{67}$ These early reports have also allowed us to link out of body experiences with deficient visual, vestibular, and multisensory processing. ${ }^{7}$ More recently, the importance of vestibular and multisensory mechanisms in out of body experiences was underlined by their occurrence in several patients with such experiences. ${ }^{3}$ In addition, vestibular illusions (of elevation, rotation, flying, lightness) and multisensory illusions (of visual limb shortening and movement) could be evoked by electrical stimulation of the same cortical area where higher stimulation currents induced out of body experiences. ${ }^{8}$ These data indicate that vestibular illusions, multisensory illusions of body parts (such as visual shortening and movement of limbs and phantom $\operatorname{limbs}^{9}$ ), and multisensory illusions of the entire body (such as out of body experiences) might share similar functional and anatomical mechanisms. ${ }^{3}$

Devinsky et al described several patients with out of body experiences caused by circumscribed brain damage and found that lesions predominantly affected the temporal lobe. ${ }^{6}$ More recently, our team analysed the lesions of several patients with out of body experiences and found that the temporo-parietal junction was affected in all patients. ${ }^{3}$ These patients had epilepsy and migraine. On the basis of these findings, our team proposed a cognitive model for out of body experiences, proposing that they are related to a failure of integration of proprioceptive, tactile, and visual information of one's body (personal space). ${ }^{3}$ This may lead to the experience of seeing one's body in a position (that is, on the bed) that does not coincide with the felt position of one's body (that is, under the ceiling). In this model disembodiment and elevated visuospatial perspective during out of body experiences are assumed to be related to additional vestibular dysfunction. ${ }^{3}$ In summary, the neurological evidence shows that out of body experiences are related to a disintegration within personal space (multisensory dysfunction) and a disintegration between personal space (vestibular) and extrapersonal space (visual) due to interference with the temporo-parietal junction.

In science the most challenging phenomena are often the ones we take for granted in our everyday lives. Excellent examples are the perception of the self and the experienced spatial unity between self and body. As argued by others, both folk psychological notions are challenged by out of body experiences. ${ }^{45}$ The reviewed evidence from neurological patients experiencing this striking dissociation between self and body shows that out of body experiences are culturally invariant phenomena that can be investigated scientifically.

The study of the self by neuroscience is in its infancy with no established models, very few data, and often not even the vocabulary to describe notions of 
the self. ${ }^{10}$ The investigation of out of body experiences and related mechanisms at the temporo-parietal junction might thus allow us to improve our neuroscientific models of self and corporeal awareness. Although many other cortical areas are involved in self processing, recent neuroimaging studies indicate a key role for the temporo-parietal junction. This is not only true for out of body experiences but also for many aspects of body and self processing, such as the integration of multisensory bodily information, the visual perception of the body, the perception of biological motion, and the distinction between self and other. ${ }^{3112}$

The experimental investigations of these multisensory and cognitive mechanisms in out of body experiences and related illusions, in combination with neuroimaging and behavioural techniques, will further our understanding of the central mechanisms of self and corporeal awareness-much as previous research was successful with respect to understanding the central mechanisms of phantom limbs. ${ }^{9}$
Olaf Blanke professor

Laboratory of Cognitive Neuroscience, Ecole Polytechnique Fédérale de Lausanne, CH-1015 Lausanne, Switzerland (olaf.blanke@epfl.ch)

Competing interests: None declared.

1 Irwin HJ. Flight of mind: A psychological study of the out-of-body experience. Metuchen, NJ: Scarecrow Press, 1985.

Blackmore SJ. Beyond the body. An investigation of out-of-body experiences. London: Heinemann, 1982.

Blanke O, Landis T, Spinelli L, Seeck M. Out-of-body experience and autoscopy of neurological origin. Brain 2004;127:243-58.

Neisser U. The five kinds of self-knowledge. Phil Psychol 1988;1:35-59.

Metzinger T. Being no one. Cambridge, MS: MIT Press, 2003.

Devinsky O, Feldmann E, Burrowes K, Bromfield E. Autoscopic phenomDevinsky O, Feldmann E, Burrowes K, Bromfiel
ena with seizures. Arch Neurol 1989:46:1080-8.

ena with seizures. Arch Neurol 1989;46:1080-8.
Brugger P, Regard M, Landis T. Illusory reduplication of one's own bodyBrugger P, Regard M, Landis T. Illusory reduplication of one's own body-
:phenomenology and classification of autoscopic phenomena. Cogn Neuropsychiatr 1997;2:19-38.

8 Blanke O, Ortigue S, Landis T, Seeck M. Stimulating illusory own-body perceptions. Nature 2002;419:269-70.

Ramachandran VS, Hirstein W. The perception of phantom limbs. Brain 1998;121:1603-30.

0 Kircher T, David A. The self in neuroscience and psychiatry. Cambridge: Cambridge University Press, 2003.

11 Decety J, Sommerville JA. Shared representations between self and other: a social cognitive neuroscience view. Trends Cogn Sci 2003;7:527-33.

12 Blanke O, Arzy S. The out-of body experience. Disturbed self processing at the temporo-parietal junction. Neuroscientist (in press).

\section{Treatment of homosexuality during apartheid}

\section{More investigation is needed into the shameful way homosexuality was treated}

Homosexuality is assuredly no advantage, but it is nothing to be ashamed of, no vice, no degradation, it cannot be classified as an illness; we consider it to be a variation of the sexual function, produced by a certain arrest of the sexual development. It is a great injustice to persecute homosexuality as a crime-and a cruelty too.

Sigmund Freud

$\mathrm{I}$ $\mathrm{n}$ the 20th century, doctors were repeatedly accomplices in state repression, brutality, and genocide. The most notorious examples of medical complicity in state abuse are the Nazi doctors who participated in genocide and the Japanese doctors who practised biological warfare. ${ }^{2}$ Included among the former were psychiatrists, who in carrying out Hitler's euthanasia programme on their patients seem to have been in a state of complete moral disarray.

Involvement of psychiatrists in state repression has if anything escalated since 1945, the most extensive example being the use of psychiatric treatment for suppression of dissenters in the Soviet Union. Similar practices arose in other east European states, China, and Cuba. Recently there have been claims of psychiatric abuse of detainees at Guantánamo Bay. ${ }^{3}$

During the apartheid years in South Africa, medical personnel were involved in abuse of prisoners, ${ }^{4}$ the most well-known case being the death in custody of Steve Biko. ${ }^{5}$ From 1969 to 1987, psychiatrists of the South African Defence Force were implicated in serious abuses, stemming from attempts to cure homosexual conscripts. ${ }^{6}$ The South African Defence Force regarded homosexuality as subversive, and severe penalties were prescribed, although attitudes were often inconsistent.

The long history of medical treatment to convert homosexuals to heterosexuals reached a peak in the seventies. The results were unconvincing, if not hopeless, and experience showed that neither patients the definition of homosexuality as an illness from the American Psychiatric Association's Diagnostic and Statistical Manual of Mental Disorders in 1973, ${ }^{9}$ interest in treatment faded and it would be thought the matter was of interest only to historians.

These developments had little influence on psychiatrists in the South African Defence Force. Militarisation of the white population escalated after the establishment of universal conscription in 1967. Conscript ranks were screened for homosexuals by doctors and chaplains. Threatened with punishment if they did not comply, they were admitted to the secretive Ward 22 at 1 Military Hospital, Voortrekkerhoogte, Pretoria. In later years, homosexual women were also selected.

Subjects were first given crude behaviour therapy. This consisted of exposure to black and white pictures of naked men while receiving electric shocks, then viewing Playboy magazine centrefolds. The shock was so intense that in one case the subject's shoes flew off. ${ }^{10}$

Homosexuals were indiscriminately grouped in the psychiatric ward with drug abusers, conscientious objectors, the politically unreliable, and the seriously mentally ill. They were often subjected to narcoanalysis, showing an ominous similarity to psychiatric re-education in the Soviet Union. Others were chemically castrated with massive doses of hormones. Drug addicts were threatened with transport to remote Greefswald (later Magaliesoord), regarded as little less than a forced labour camp.

Accounts exist of suicide during treatment and after discharge. The most well known is Jean Erasmus, who killed himself after providing detailed information about the programme.

The next stage in treatment went beyond any justifiable basis. Recurrent allegations have been made that between 1969 and 1987 approximately 900 men and 